\title{
Medikamentell behandling i oppfølging etter selvmordsforsøk
}

\author{
Ved O dd Lingjærde
}

De aller fleste selumordsforsøk skjer hos personer med psykisk lidelse, oftest depresjon. Ioppfølgingen er det viktig at denne lidelsen også blir gitt optimal medikamentell behandling, for i størst mulig grad å hindre tilbakefall. Det gjelder i saerlig grad ved depressiv og bipolar lidelse, men også ved f.eks. schizofreni.

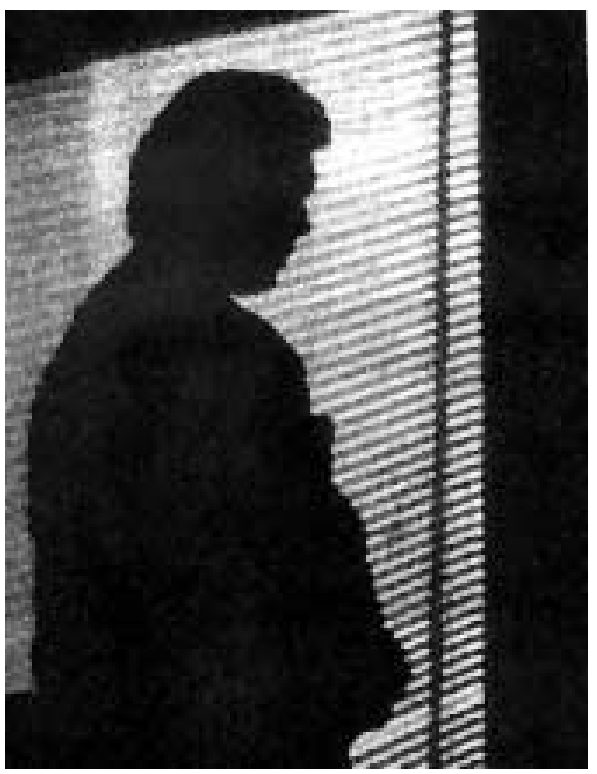

O mkring $70 \%$ av alle suicid skjer i forbindelse med depresjon; en stor del av de resterende skjer hos pasienter med annen diagnostiserbar psykisk lidelse som schizofreni, alvorlig personlighetsforstyrrel se eller stoffmisbruk/alkoholisme. A Itfor ofte kan det påvises at den suiciderte ikke har fått adekvat behandling, f.eks. med psykofarmaka, før suicidet eller etter suicidforsøket. M en om adekvat behandling ikke har vært gitt før, må det i allefall igangsettes snarest mulig etter et suicidforsøk. Tidligere suicidforsøk er den største risikofaktor for ny suicidal atferd, uansett diagnose, og risikoen er størst i de første 6-12 månedene etter et forsøk. Siden

suicidal atferd i de fleste tilfeller er knyttet til depresjoner, vil videre medikamentell behandling av depressive lidelser - enten depresjon som ledd i bipolar ("maniskdepressiv") lidelse eller "rene" unipolare depressive lidelser - bli hovedtemaet i det følgende, med kortere omtale av schizofreni og personlighetsforstyrrelse.

\section{Biologiske prediktorer}

$M$ arie $\AA$ sberg og medarbeidere viste allerede på 70-tallet at depressive som hadde gjort alvorlige suicidforsøk, hadde spesielt lavt innhold i spinalvæsken av serotoninets hovedmetabolitt 5-hydroksyindoleddiksyre (5H IA A ) ( $\AA$ sberg et al. 1976). Dette funnet, som kan tas som indikasjon på at suicidale depressive pasienter har abnormt lav omsetning av serotonin, er bekreftet av en rekke andre. Det er senere vist at lav omsetning av serotonin i hjernen forsåvidt ikke er noe spesifikt for depressive pasienter, men at det på tvers av diagnoser korrelerer med spesielle personlighetstrekk som man nettopp ville forvente hos personer som begår suicid: aggressivitet og impulsivitet. Lav omsetning av serotonin er ikke noe mål på alvorlighetsgraden av depresjon, selv om det ses oftest ved de "egentlige" depresjonene som tidligere ble betegnet som endogene, som ledd i manisk-depressiv lidelse. Det er ellers viktig å være oppmerksom på at lav omsetning av serotonin ikke synes å korrelere direkte med suicidale tanker, men snarere med suicidal atferd, og at veien fra suicidale tanker til suicidal atferd kan variere betydelig fra person til person. Veien synes å være særlig kort hos personer med lav omsetning av serotonin.

M åling av 5H I A A i spinalvæsken etter et selvmordsforsøk er muligens den beste prediktor man har av fremtidig alvorlig suicidrisiko. Dessverre er det ingen tradisjon for å gjøre slik undersøkelse i N orge, mens det i Sverige er mer vanlig.

$U t$ fra det som er sagt ovenfor, er det rimelig å tro - selv om det er vanskelig å dokumentere - at medikamentell forebygging av suicidal atferd skjer best med sterke serotonerge medikamenter som klomipramin eller selektive serotonin reopptakshemmere (SSRI). Det er derimot holdepunkter for at det rene noraddrenerge antidepressivum maprotilin (ikke markedsført i N orge) kan forebygge nye episoder av depresjon mens det samtidig øker risikoen for suicidal atferd (R ouillon et al. 1989). Til en viss grad ser det altså ut til at tendensen til suicidal atferd på den ene side, og grad av depresjon på den annen side er knyttet til forskjellige nevrobiologiske prosesser, og slett ikke står i noe konstant forhold til hverandre.

\section{Bipolar lidelse}

Bipolar lidelse, som svarer til det tidligere begrepet manisk-depressiv lidelse, innebærer en meget høy livstidsrisiko for suicid, anslagsvis 15-25 \%. M en heldigvis har man ved denne lidelsen et medikament med meget godt dokumentert forebyggende effekt både på maniske og depressive episoder og generelt på suicidrisikoen, nemlig litium. En nyere oversikt konkluderer med at kontinuerlig litiummedikasjon reduserer suicidrisikoen ved alvorlig bipolar lidelse med ca. 85 \% (Baldessarini et al. 1999). Etter avbrutt litiumbehandling - spesielt hvis det skjer brått - øker suicidrisikoen dramatisk, særlig første året. Litium har ikke like godt dokumentert effekt ved unipolar depressiv lidelse.

Litium er ikke lenger det enerådende stemningsstabiliserende medikament til bruk ved bipolar lidelse. A ntiepileptika som karbamazepin, og senere særlig valproat, er aktuelle alternativer, spesielt i behandling av akutt mani, men også som langtidsprofylakse. Der har de imidlertid ikke like godt dokumentert effekt som litium. $0 \mathrm{~g}$ spesielt er det ikke dokumentert at de har samme suicidforebyggende effekt. Enkelte langtidsstudier tyder tvert imot på at karbamazepin har klart mindre suicidforebyggen de effekt en n litium (Baldessarini et al. 1999). Dette kan henge sammen med at litium har en spesiell antiaggressiv og "antisuicidal" effekt, formidlet gjennom dets virkning på serotoninsystemet - en virkning som karbamazepin og andre antiepileptika ikke har. O gså her må vi altså regne med at det kan være en forskjell mellom forebyggende virkning overfor depresjon og mani, og forebyggende virkning overfor suicidal atferd, og at litium er klart best når det gjelder det siste.

A lle som har hatt flere episoder av bipolar affektiv lidelse, bør i første omgang settes på litium - og ikke minst gjelder det selvsagt pasienter som har gjort suicidforsøk. H vis litium alene ikke har nok effekt, kan det gistillegg av et annet stemningsstabiliserende medikament, som valproat. M en litium bør helst beholdes, særlig med tanke på den suicidforebyggende 
virkningen. H vis litium tåles dårlig, får man heller redusere dosen. Det er ikke gitt at den suicidforebyggende virkning krever samme plasmakonsentrasjonen som den mani- og depresjonsforebyggende virkning.

\section{Unipolar depressiv lidelse}

Retrospektive analyser av suiciderte depressive personer viser at bare et mindretall av dem har fătt adekvat antidepressiv behandling i tiden før suicidet (I sacsson et al. 1997, A gerskov A ndersen 2000). På den annen side viste bl.a. det velkjente G otlandprosjektet at 2-årig opptrening av allmenn praktikere i diagnostikk og behandling av depresjoner førte til redusert antall suicid - riktignok bare blant kvinner (Rutz et al. 1989, Rihmer et al. 1995). U nderdiagnostisering og underbehandling av depresjoner er derfor åpenbart en meget viktig faktor i relasjon til forekomst av suicid, og adekvat antidepressiv behandling av største betydning for forebygging av suicidal atferd hos personer som har gjort suicidforsøk i forbindelse med depressiv lidelse.

$\mathrm{N}$ år det gjelder valg av antidepressivum, må man ta hensyn til at "gammeldagse" tricykliske antidepressiva (TCA ) er langt mer toksiske i overdose enn nyere antidepressiva som SSRI, venlafaxin, mianserin og moklobemid, og tidligere var et TCA ikke sjelden nettopp det medikament som en depressiv pasient brukte til å begå selvmord (Retterstøl 1989). Selv om det er holdepunkter for at TCA er noe mer effektive enn nyere antidepressiva ved de alvorligste former for depresjon (Lingjærde 2001), bør man derfor helst unngå TCA $\emptyset$ nsker man allikevel å satse på et TCA , som f.eks. klomipramin, må medikamentet tas hånd om av en annen person enn pasienten selv.

$\mathrm{N}$ år man både tar hensyn til den akutte toksisitet og til det som tidligere er sagt om betydningen av sterk serotonerg virkning, tilsier det at man vanligvis bør velge en SSRI. Blant de aktuelle SSRI er det ingen sikker forskjell i generell antidepressiv eller suicidforebyggende virkning. $A v$ andre nyere antidepressiva kan venlafaxin være et aktuelt alternativ, siden det synes å ha bedre generell antidepressiv virkning enn SSRI ved alvorligere depresjoner (Lingjærde 2001), men det er usikkert hvor effektivt det er som suicidforebyggen de medikament.
Kan noen antidepressiva forsterke risikoen for suicid? Det vakte en del bekymring da Teicher et al. (1990) rapporterte at noen depressive pasienter på fluoxetin utviklet nærmest tvangspregede suicidaltanker - skjønt ingen av pasientene begikk suicid. Senere er det også rapportert fra andre at det en sjelden gang kan opptre forsterkede suicidaltanker på SSRI, men det synes ikke som dette er ledsaget av økt suicidal atferd. Senere omfattende analyser fra placebokontrollerte forsøk har for øvrig ikke kunnet bekrefte at verken SSRI eller andre antidepressiva generelt sett forsterker suicidale tanker eller suicidal atferd - heller tvert imot (Beasley et al. 1992). M en i sjeldne tilfelle kan det altså antagel ig komme tvangspregede suicidal tanker.

\section{Schizofreni}

O mtrent hver tien de schizofrene pasient ender sitt liv med suicid, og som oftest i forbindelse med depresjon (Siris 2000). Det kan være mange årsaker til at en schizofren person blir deprimert. D epresjon hos schizofrene er vist å korrelere med positive psykotiske symptomer, og må derfor antas å kunne være sekundære til slike. Forhol det til negative symptomer er mer uklart, og her er det en viss overlapping i symptomatologien som kan gjøre det vanskeligå sette noe klart skille. D et er ellers viktig å være oppmerksom på at en akinetisk-dysforisk tilstand kan være uttrykk for overdosering med antipsykotika, som en slags parkin sonisme uten muskulære symptomer. A kathisi (muskulær uro, "mangl ende evne til å kunne sitte stille"), som også hører til de ekstrapyramidal e bivirkninger, kan være så plagsom at det kan føre til suicidaltanker og i sjeldne tilfeller til suicidal atferd. Et kronisk demoraliseringssyndrom som av og til utvikler seg hos schizofrene, er også en klar risikofaktor. Endelig har man sel vsagt depressive trekk som ledd i schizo-affektiv lidelse, der grensen mot bipolar lidelse er uklar.

Den videre medikamentelle behandling av en schizofren som har gjort suicidforsøk, eller har vist klare suicidale tanker, må først og fremst ta utgangspunkt i en vurdering av årsaken til dette. Ligger årsaken - helt ellert delvis - i overdosering av antipsykotika, må man selvsagt redusere dosen eller gå over til et medikament med mindre tendens til uheldige bivirkninger, særlig akathisi. Ligger ărsaken i en akutt, skremmende psykotisk tilstand, må denne gis adekvat antipsykotikabehandling. A ntidepressiva, fortrinnsvis SSRI, kan være effektive mot negative symptomer, uten å forverre de positive, og kan også være effektive mot "ekte" depressive symptomer, men ikke nevneverdig mot antipsykotikafremkalt akinetisk-dysforisk syndrom.

Det er gjort mange forsøk på å finne om ulike antipsykotika kan ha en direkte antidepressiv og eventuelt suicidforebyggende virkning ved schizofreni, i tillegg til den indirekte virkning via bedring av psykosen. Resultatene er uklare, bl a fordi det er vanskeligå skille mellom en direkte og en indirekte virkning på depresjonen, og fordi noen schizofrene får snarere en forverring pga overdosering. Det som imidlertid er godt dokumentert, er at klozapin har en klar suicidforebyggen de effekt, hva enten den nå skyldes en direkte eller indirekte antidepressiv virkning ( $M$ eltzer \& O kayli 1995). O gså olanzapin, risperidon ( $\mathrm{i}$ ikke for høy dose!) og ziprasidon kan ha antidepressiv virkning hos schizofrene, og i hvert fall bedre enn et typisk førstegenerasjons lavdoseantipsykotikum som haloperidol (Siris 2000).

\section{Personlighetsforstyrrelser}

Suicidforsøk er ikke uvanlig hos personer med personlighetsforstyrrelse, men fullført suicid forekommer også, kanskje først etter flere forsøk. Risikoen er antagelig størst ved emosjonelt ustabil personlighetsforstyrrelse( ("borderlinetilstand"). Virkningen av psykofarmaka er her ikke særlig godt undersøkt. Best undersøkt er antipsykotika, som i en del forsøk har 
vist signifikant bedre effekt enn placebo, særlig på psykosenære symptomer. M en bedring er også konstatert på depresjon, og dermed kan antipsykotika sannsynligvis også redusere suicidrisiko. N yere antipsykotika som klozapin og olanzapin har antagelig bedre effekt enn de tradisjonelle. Blant antidepressiva har T CA usikker effekt, mensSSRI er vist å kunne ha effekt på depresjon, impulsivitet, aggressi vitet og suicidalitet.

\section{Referanser}

A gerskov A ndersen U. Psychopharmacologic and other medical treatment in persons who committed suicide - A register linkage study. D octoral dissertation, Institute of Public $\mathrm{H}$ ealth, Clinical Pharmacology, Faculty of $\mathrm{H}$ ealth Sciences, U niversity of Southern Denmark, 0 dense 2000 (A bstrakt i $\mathrm{N}$ ordic Journal of Psychiatry 2001; 55: 59)

Bal dessarini RJ, Tondo L, $H$ ennen J. Effects of lithium treatment and its discontinuation on suicidal behavior in bipolar manic-depressive disorders. Journal of C linical Psychiatry 1999; 60 (suppl 2) : 77-84

Beasley CM jr, Dornseif BE, Bosomworth JC, Sayler ME, Rampey A H jr, H eiligenstein JN, Thompson
VL, M urphy DJ, M asica DN . Fluoxetine and suicide: a meta-analysis of controlled trials of treatment for depression. International C linical Psychopharmacology 1992; 6, (suppl 6) : 35-57

I sacsson $G, H$ olmgren $P$, D ruid $H$, Bergman $U$. The utilization of antidepressants - a key issue in the prevention of suicide: an analysis of 5281 suicides in Sweden during the period 1992-1994. A cta Psychiatrica Scandinavica 1997; 96: 94-100

Lingjærde 0 . Psykofarmaka. M edikamentell behandling av psykiske lidelser, 4. utgave. Kristiansand: $\mathrm{H}$ øyskoleforlaget, 2001.

M eltzer HY, O kayli G. R eduction of suicidality during clozapine treatment of neuroleptic-resistant schizophrenia: impact of risk-benefit assessment. A merican Journal of Psychiatry 1995;152: 183-190

Retterstøl N . N orwegian data on death due to overdose of antidepressants. A cta Psychiatrica Scandinavica 1989; 80 (suppl. 354): 61-68

Rihmer Z, Rutz W, Pihlgren H. D epression and suicide on $\mathbf{G}$ otland. A $\boldsymbol{n}$ intensive study of all suicides before and after a depression-training programme for general practitioners. Journal of A ffective Disorders 1995; 35: 147-152

Rouillon F, Phillips R, Serrurier E, A nsart E, G erard $J M$. Prophylactic efficacy of maprotiline on relapses of unipolar depression. L'Encéphale 1989; 15: $527-534$
Rutz W, Knorring L v, W ålinder J. Frequency of suicide on $\mathrm{G}$ otland after systematic postgraduate education of general practitioners. A cta Psychiatrica Scandinavica 1989; 80: 151-154

Siris SG. D epression in schizophrenia: Perspective in the era of "atypical antipsychotic agents". A merican Journal of Psychiatry 2000; 157: 13791389

Teicher M H, G lod C, C ole JO. Emergence of intense suicidal preoccupation during fluoxetine treatment. A merican Journal of Psychiatry 1990; 147: $207-210$

Å sberg M , Träskman L, T horén P. 5-H IA A in the cerebrospinal fluid: A biochemical suicide predictor? A rchives of G eneral Psychiatry 1976; 33: 1193-1197

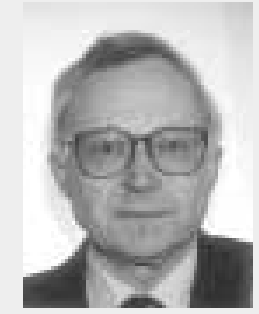

O dd Lingjærde er spesialist i psykiatri med særlig interesse for psykofarmakologi og biologisk psykiatri. H an har vært professor i psykiatri

i Tromsø og senere i 0 slo, og avdelingsoverlege ved A sgård sykehus og

G austad sykehus. Pensjonert fra 1999. H ar bl.a. skrevet boken "Psykofarmaka", som kommer i 4. reviderte utgave i 2001.

\section{Forts. fra s. 22}

pasi entene og deres pårørende. Denne "gaven" kan gjøre det mulig for pasientene å velge livet, for å bli møtt i sine grunnleggende behov gir livet mening. $N$ år pasi entene og pårørende ikke blir møtt, som de hadde en forventning om da de kom til sykehuset, øker lidel sen. D ette kan bety at mangel på bekreftelse fra helsepersonalet, fravær av et felleskap med helsepersonal et, fravær av trøst og håp fra helsepersonalet kan være med på å $ø$ ke risikoen for selvmord $\mathrm{i}$ den tiden pasienten er innlagt på sykehuset og like etter utskriving.

Forhåpentligvis kan den kunnskapen som nå foreligger, være et bidrag til videre refleksjon om psykiatrisk pleie og behandling av pasienter som har selvmordstanker og pasienter som har gjort selvmordsforsøk.

H ovedveileder til min doktorgrad har vært professor A strid N orberg, Institution för 0 mvårnad, U meå U niversitet, Sverige.
A nne-G rethe Talseth er førsteamanuensis ved A vde ling for helsefag, $\mathrm{H} ø g$ skolen i Tromsø. H un er psykiatrisk sykepleier og med.dr. (U meå universitet, 2001). Hennes doktoravhandling handler om relasjonen mellom selvmordspasienter, deres

pårørende og helsepersonell i et psykiatrisk sykehus.

\section{Referanser}

Dawkins K. T he interaction of ethnicity, sociocultural factors, and gender in clinical psychopharmacology. Psychopharmacology Bulletin 1996; 32: 283-289.

Funahashi T, Ibuki $Y, D$ omon $Y, N$ ishimura $T$, A kehashi $D$, Sugiura H. A clinical study on suicide among schizophrenics. Psychiatry and Clinical N eurosciences 2000; 54: 173-179.

Jobes DA . C ollaborating to prevent suicide: a clinical-research perspective. Suicide and LifeThreatening Behavior 2000; 30: 8-17.

$M$ ishler EG. R esearch Interviewing: Context and N arrative. London: H arvard U niversity Press, 1986.
Ricoeur P. Interpretation T heory: D iscourse and the Surplus of M eaning. Fort W orth Texas: Christian U niversity Press, 1976.

Talseth A G, Lindseth A, Jacobsson L, N orberg A . $N$ urses' narrations about suicidal psychiatric inpatients. N ordic Journal of Psychiatry 1997; 51: 359-364.

Talseth A G, Lindseth A, Jacobsson L, N orberg A. $T$ he meaning of suicidal psychiatric in-patients' experiences of being cared for by mental health nurses. Journal of A dvanced $N$ ursing 1999; 29: 1034-1041.

Talseth A G, Jacobsson L, N orberg A. Physicians' stories about suicidal psychiatric inpatients. Scandinavian Journal of C aring Sciences 2000; 14: $275-283$.

Talseth A G , N orberg A, Jacobsson L. T he meaning of suicidal psychiatric inpatients' experiences of being treated by physicians. Journal of A dvanced N ursing 2001; 34: 96-106.

Talseth A G, G ilje F, N orberg A . 'B eing met'A passageway to hope for relatives of patients at risk of committing suicide: A phenomenological hermeneutic study. M anuscript submitted 2001. 